\title{
Technetium Tc-99m Mebrofenin
}

National Cancer Institute

\section{Source}

National Cancer Institute. Technetium Tc-99m Mebrofenin. NCI Thesaurus. Code C80064.

A radioconjug ate composed of the iminodiacetic acid derivative mebrofenin bound to an isotope of the synthetic element technetium (Tc). Upon administration and rapid clearance from the circulation, technetium Tc $99 \mathrm{~m}$ mebrofenin is secreted into the hepatobiliary system, emitting gamma rays that are detectable with planar scintigraphy or single photon emission computer tomography (SPECT). Mebrofenin has no pharmacological effect at the recommended dosage for diagnostic imagining. 